\title{
ANALISIS HUBUNGAN KETUBAN PECAH DINI TERHADAP KEJADIAN ASFIKSIA DI RSU BUDI KEMULIAAN
}

\section{ANALYSIS CORRELATION OF PREMATURE RUPTURE OF MEMBRANES WITH INCIDENCE OF ASPHYXIA AT BUDI KEMULIAAN GENERAL HOSPITAL}

\author{
${ }^{1}$ Dwi Ratna Prima, ${ }^{1}$ Prila Hasdela, ${ }^{2}$ Irma Sari Lubis \\ ${ }^{1}$ Sekolah Tinggi Ilmu Kesehatan Budi Kemuliaan \\ ${ }^{2}$ Rumah Sakit Umum Budi Kemuliaan \\ Korespondensi: penjamustikbk@gmail.com
}

\begin{abstract}
Premature rupture of membranes (PROM) is a state of rupture of the amniotic membrane, can occur in preterm or term pregnancy. Under normal circumstances $8-10 \%$ of pregnant women will experience with PROM. PROM occurs in premature pregnancy of 1\%. Complications arising of PROM can occur maternal or neonatal infection, preterm labor, hypoxia or asphyxia, fetal deformity, increased incidence of SC or failure of normal labor. The purpose of this research is to analyze the correlation of PROM with incidence of asphyxia at Budi Kemuliaan Hospital in 2018 Period. This study used an analytical survey with a cross sectional approach, using secondary data. The sample in this study was 66 babies. The analysis technique was carried out bivariately using chi square formula. The results showed that of 66 asphyxia infants there were $38(58 \%)$ who experienced with PROM and 28 (42\%) did not experience with PROM. The results of the statistical test between correlation of PROM to incidence of asphyxia based on the Age of Mother obtained a value of $p$ value $=0.026$ $<0.05$, there was a correlation between the age of maternity and the incidence of asphyxia. Correlation of PROM to incident asphyxia based on parity obtained a value of $p$ value $=0.0107<0.05$. Correlation of PROM to incidence of asphyxia based on age of pregnancy $p$ value $=0.988>0.05$. Correlation of PROM to incidence of asphyxia based on Infection were $p$ value $0.451=>0.05$. Correlation of PROM to incidence of asphyxia based on the history of Severe Fetus obtained p value $0.434=>0.05$.
\end{abstract}

Keywords: PROM, Asphyxia

ABSTRAK

Ketuban Pecah Dini (KPD) adalah keadaan pecahnya selaput ketuban, dapat terjadi pada kehamilan preterm ataupun aterm. Dalam keadaan normal 8- 
$10 \%$ perempuan hamil aterm akan mengalami KPD. KPD terjadi pada kehamilan Prematur sebesar $1 \%$. Komplikasi yang timbul akibat KPD dapat terjadi infeksi maternal ataupun neonatal, persalinan prematur, hipoksia atau asfiksia, deformitas janin, meningkatnya insiden SC atau gagalnya persalinan normal. Tujuan penelitian ini untuk menganalisis hubungan KPD terhadap kejadian Asfiksia periode 2018 di RSU Budi kemuliaan. Penelitian ini menggunakan survey analitik dengan pendekatan cross sectional, menggunakan data sekunder. Sampel penelitian ini sejumlah 66 bayi. Tehnik analisis dilakukan secara bivariat menggunakan rumus chi square. Hasil penelitian menujukkan bahwa dari 66 bayi yang mengalami asfiksia ada 38 (58\%) yang mengalami KPD dan 28 (42\%) tidak mengalami KPD. Hasil uji statistik antara hubungan ketuban pecah dini terhadap asfiksia berdasarkan usia ibu didapatkan nilai $p$ value=0,026 $<0,05$ terdapat hubungan antara usia ibu bersalin dengan kejadian asfiksia. Hubungan ketuban pecah dini terhadap asfiksia berdasarkan paritas didapatkan nilai $p$ value $=0,107>0,05$. Hubungan ketuban pecah dini terhadap asfiksia berdasarkan Usia Kehamilan didapatkan nilai $p$ value $=0,988>0,05$. Hubungan ketuban pecah dini terhadap asfiksia berdasarkan Infeksi didapatkan nilai $p$ value $0,451=>0,05$. Hubungan ketuban pecah dini terhadap asfiksia berdasarkan riwayat gawat janin didapatkan nilai $p$ value $0,434=>0,05$.

\section{Kata Kunci : KPD, Asfiksia}

\section{PENDAHULUAN}

Ketuban Pecah Dini adalah keadaan pecahnya selaput ketuban, dapat terjadi pada kehamilan preterm ataupun aterm. Dalam keadaan normal 8-10\% perempuan hamil aterm akan mengalami Ketuban Pecah Dini. Ketuban Pecah Dini terjadi pada kehamilan Prematur sebesar $1 \%$. Pada usia kehamilan 28-34 minggu 50\% terjadi persalinan dalam 24 jam dan pada usia kehamilan kurang dari 26 minggu pesalinan terjadi dalam 1 minggu (Prawirohadjo, 2014). Komplikasi yang timbul akibat Ketuban Pecah Dini bergantung pada usia kehamilan. Dapat terjadi infeksi maternal ataupun neonatal, persalinan prematur, hipoksia atau asfiksia karena kompresi tali pusat, deformtias janin, meningkatnya insiden SC atau gagalnya persalinan normal (Prawirohadjo, 2014). Kejadian bayi baru lahir 
Asfiksia menempati penyebab diantaranya hidup dengan kematian bayi terbesar ke 3 di morbiditas jangka panjang seperti dunia dalam periode awal cerebral palsy, retardasi mental, kehidupan (WHO, 2012). Setiap dan gangguan belajar (DepKes RI, tahunnya kira-kira 3\% (3,6 juta) 2008).

dari 120 juta bayi baru lahir mengalami asfiksia, hampir 1 juta bayi ini meninggal (Wiknjosastro., 2008). WHO menyatakan bahwa AKB akibat asfiksia di kawasan Asia Tenggara menempati urutan kedua yang paling tinggi yaitu sebesar 142 per 1000 setelah Afrika. Indonesia merupakan negara dengan AKB dengan asfiksia tertinggi kelima untuk negara ASEAN pada tahun 2011 yaitu 35 per 1000, dimana Myanmar 48 per 1000, Laos dan Timor Laste 48 per 1000, Kamboja 36 per 1000 (Maryunani, 2013). Pada tahun 2003 menyebutkan bahwa asfiksia menempati urutan ke-6 yaitu sebanyak $8 \%$ sebagai penyebab kematian anak diseluruh dunia setelah pneumonia, malaria, sepsis neonatorum dan kelahiran prematur. Diantara bayi yang masih bisa bertahan hidup setelah asfiksia setidaknya satu juta

Hasil SDKI tahun 2012 angka kematian ibu diperkirakan sebesar 359 kematian maternal per 100.000 kelahiran hidup untuk periode 2008-2012. Analisis tren rasio kematian maternal menunjukan penurunan dari SDKI 1994 sampai dengan SDKI 2007. Namun, gambaran ini meningkat pada SDKI 2012. Sedangkan untuk angka kematian bayi Data SDKI 2012 menunjukkan kematian bayi untuk periode 5 tahun sebelum survei (2008-2012) adalah 32 kematian per 1.000 kelahiran hidup. Angka kematian balita dan kematian anak.

Di Provinsi DKI Jakarta Angka kematian bayi di DKI Jakarta dari tahun ke tahun terus mengalami penurunan. AKB di Provinsi DKI Jakarta menurut data Seksi Kesehatan Keluarga Dinkes DKI Jakarta AKABA DKI Jakarta tahun 2017 yaitu sebesar 3 balita 
per 1.000 kelahiran hidup pada tahun 2017, dibandingkan tahun 2016 sebesar 4 bayi mati per 1.000 kelahiran hidup. Target MDGs untuk AKB pada tahun 2015 sebesar 23 kematian bayi per 1.000 kelahiran hidup, dan artinya Provinsi DKI Jakarta telah mencapai target MGDs dengan tujuan menurunkan angka kematian bayi dalam kurun waktu 1990-2015.

\section{METODE}

Penelitian ini menggunakan metode analitik dengan pendekatan cross sectional. Data yang diperoleh adalah data sekunder yaitu data yang diambil dari catatan medik (medical record). Populasi pada penelitian ini adalah ibu bersalin dengan KPD yang mengalami asfiksia pada bayi baru lahir. Waktu penelitian selama periode Januari - Desember 2018 yaitu sebanyak 66 bayi terjadi asfiksia, dan terdapat 38 (58\%) yang mengalami KPD. Data yang diperoleh kemudian dikumpulkan, diolah, diedit untuk memudahkan analisa, setelah itu dibuat tabulasi dan analisa dengan uji statistik (chai square test).

\section{HASIL DAN PEMBAHASAN}

Tabel 1. Distribusi Frekuensi Karakteristik Responden

\begin{tabular}{lcc}
\hline \multicolumn{1}{c}{$\begin{array}{c}\text { Karakteristik } \\
\text { Responden }\end{array}$} & $\mathrm{n}$ & $\%$ \\
\hline 1. Usia Ibu & & \\
\hline Usia < 20tahun & 10 & $15 \%$ \\
\hline Usia 20-35 tahun & 37 & $56 \%$ \\
\hline Usia > 35tahun & 19 & $29 \%$ \\
\hline Jumlah & 66 & $100 \%$ \\
\hline 2. Paritas & & \\
\hline Nulipara & 18 & 27 \\
\hline Primipara & 20 & 30 \\
\hline Multipara & 24 & 37 \\
\hline Grande Multipara & 4 & 6 \\
\hline Jumlah & 66 & $100 \%$ \\
\hline 3. Usia Kehamilan & & \\
\hline Kurang Bulan & 26 & 39 \\
\hline Cukup Bulan & 40 & 61 \\
\hline Jumlah & 66 & 100 \\
\hline 4. Infeksi & & \\
\hline Leukosit (10.000) & 17 & $26 \%$ \\
\hline Leukosit (10.000- & 28 & $42 \%$ \\
15.000) & & \\
\hline Leukosit (>15.000) & 21 & $32 \%$ \\
\hline Jumlah & 66 & $100 \%$ \\
\hline 5. Riwayat Gawat & & \\
\hline \multicolumn{1}{c}{ Janin } & & \\
\hline Takikardi & 0 & $0 \%$ \\
\hline Bradikardi & 27 & $59 \%$ \\
\hline Normal & 66 & $100 \%$ \\
\hline Jumlah & & \\
\hline & & \\
\hline
\end{tabular}


Tabel 2. Distribusi Frekuemsi Karakteristik Berdasarkan Ketuban Pecah

Variabel : Jumlah Persentase

\begin{tabular}{lcc}
\hline KPD & 38 & $58 \%$ \\
\hline Tidak KPD & 28 & $42 \%$ \\
\hline Total & 66 & $100 \%$
\end{tabular}

Berdasarkan tabel 2 di dapatkan hasil penelitian bahwa Ketuban Pecah yang berpengaruh terhadap asfiksia yaitu Ketuban Pecah Dini. Ibu yang mengalami KPD sebanyak 38 (58\%) dan pada ibu yang tidak mengalami KPD sebanyak 28 (42\%).

Tabel 3. Distribusi Frekuensi Hubungan Ketuban Pecah Dini Terhadap Kejadian Asfiksia

\begin{tabular}{|c|c|c|c|c|c|}
\hline Variabel : & KPD & $\%$ & Tidak KPD & $\%$ & P value \\
\hline 1. Usia & & & & & \multirow{5}{*}{0,026} \\
\hline Usia $<20^{\text {th }}$ & 2 & $20 \%$ & 8 & $80 \%$ & \\
\hline Usia $20-35^{\text {th }}$ & 25 & $68 \%$ & 12 & $32 \%$ & \\
\hline Usia $>35^{\text {th }}$ & 11 & $58 \%$ & 8 & $42 \%$ & \\
\hline Total & 38 & $100 \%$ & 28 & $100 \%$ & \\
\hline \multicolumn{6}{|l|}{ 2. Paritas } \\
\hline Nulipara & 12 & $67 \%$ & 6 & $33 \%$ & \multirow{5}{*}{0,107} \\
\hline Primipara & 12 & $60 \%$ & 8 & $40 \%$ & \\
\hline Multipara & 14 & $58 \%$ & 10 & $42 \%$ & \\
\hline Grande Multipara & 0 & $0 \%$ & 4 & $0 \%$ & \\
\hline Total & 38 & $100 \%$ & 28 & $100 \%$ & \\
\hline \multicolumn{6}{|l|}{ 3.Usia Kehamilan } \\
\hline Kurang bulan & 15 & $58 \%$ & 11 & $42 \%$ & \multirow{3}{*}{0,988} \\
\hline Cukup Bulan & 23 & $58 \%$ & 17 & $42 \%$ & \\
\hline Total & 38 & $100 \%$ & $28 \%$ & $100 \%$ & \\
\hline \multicolumn{6}{|l|}{ 4. Infeksi } \\
\hline $\begin{array}{l}\text { Leukosit } \\
(<10.000)\end{array}$ & 12 & $71 \%$ & 5 & $29 \%$ & \multirow{4}{*}{0,451} \\
\hline $\begin{array}{l}\text { Leukosit } \\
(10.000-15.000)\end{array}$ & 15 & $54 \%$ & 13 & $46 \%$ & \\
\hline $\begin{array}{l}\text { Leukosit } \\
(>15.000)\end{array}$ & 11 & $52 \%$ & 10 & $48 \%$ & \\
\hline Total & 38 & $100 \%$ & 28 & $100 \%$ & \\
\hline $\begin{array}{l}\text { 5. Riwayat gawat } \\
\text { janin }\end{array}$ & KPD & $\%$ & Tidak KPD & $\%$ & P value \\
\hline Takikardi & 0 & $0 \%$ & 0 & $0 \%$ & \multirow{4}{*}{0,434} \\
\hline Bradikardi & 24 & $62 \%$ & 15 & $38 \%$ & \\
\hline Normal & 14 & $52 \%$ & 13 & $48 \%$ & \\
\hline Total & 38 & $100 \%$ & 28 & $100 \%$ & \\
\hline
\end{tabular}


Berdasarkan tabel 3 di dapatkan hasil penelitian bahwa Usia Ibu yang berpengaruh terhadap kejadian asfiksia yaitu terjadi pada usia 20-35 tahun sebanyak 37 (56\%), paritas yang berpengaruh terhadap kejadian asfiksia yaitu terjadi pada multipara sebanyak $24(37 \%)$, usia kehamilan yang berpengaruh terhadap kejadian asfiksia yaitu terjadi pada usia kehamilan cukup bulan sebanyak 40 (61\%), infeksi yang berpengaruh terhadap kejadian asfiksia yaitu terjadi dilihat dari jumlah leukosit (10.000-15.000) sebanyak 28 $(42 \%)$, riwayat gawat janin yang berpengaruh terhadap kejadian asfiksia yaitu terjadi gawat janin bradikardi sebanyak 39 (59\%).

Hasil uji statistik antara hubungan ketuban pecah dini terhadap asfiksia berdasarkan usia ibu didapatkan nilai $p$ value $=0,026<0,05$ terdapat hubungan antara usia ibu bersalin dengan kejadian asfiksia. Hubungan ketuban pecah dini terhadap asfiksia berdasarkan paritas didapatkan nilai $p$ value $=$ 0,107>0,05. Hubungan ketuban pecah dini terhadap asfiksia berdasarkan Usia Kehamilan didapatkan nilai $p$ value $=0,988>$ 0,05. Hubungan ketuban pecah dini terhadap asfiksia berdasarkan Infeksi didapatkan nilai $p$ value $0,451=>0,05$. Hubungan ketuban pecah dini terhadap asfiksia berdasarkan riwayat gawat janin didapatkan nilai $p$ value $0,434=>0,05$.

Menurut Wiknjosastro (2005), umur ibu pada saat hamil merupakan salah satu faktor yang menentukan tingkat risiko kehamilan dan persalinan termasuk kejadian KPD. Umur ibu reproduksi ibu yang optimal pada umur 20 - 35 tahun, karena pada usia tersebut organ reproduksi sudah berfungsi secara optimal. Jika seorang wanita hamil pada umur $<20$ tahun, dianggap sebagai kehamilan risiko tinggi karena alat reproduksi belum siap untuk hamil sehingga mempengaruhi pembentuk-an selaput ketuban 
menjadi abnormal. Sedangkan pada usia > 35 tahun terjadi penurunan kemampu-an organorgan reproduksi yang berpengaruh pada proses embriogenesis sehingga selaput ketuban lebih tipis yang memudahkan untuk pecah sebelum waktunya. Berdasarkan hasil analisis, hubungan ketuban pecah dini terhadap asfiksia didapatkan hasil terbanyak dengan usia 20-35 tahun. Di lihat dari segi ibu yang mengalami KPD sebanyak 25 (68\%) dan pada ibu yang tidak mengalami KPD sebanyak $12(32 \%)$.

Penelitian ini sejalan dengan Hasil penelitian Natiqotul Fatkhiyah (2008) menunjukkan bahwa sebagian besar responden berumur 20-35 tahun yaitu ada 59 orang $(54,6 \%)$, sedangkan umur $>35$ tahun ada 17 responden $(15,7 \%)$ dan yang berumur $<20$ tahun ada 32 orang $(39,6 \%)$.

Menurut Manuaba (2008) persalinan dengan KPD bisa disebabkan oleh multi / grandemulti, overdistensi uterus (hidroamnion, kehamilan ganda), disproporsio sefalo pelvis, kelainan letak (lintang dan sungsang). Oleh sebab itu, ketuban pecah dini memerlukan pengawasan yang ketat dan kerja sama antara kelurga dan penolong (bidan dan dokter) karena dapat menyebabkan bahaya infeksi intrauterin yang mengancam kesehatan ibu dan janin. Pendapat Manuaba (2008) tersebut sesuai dengan hasil penelitian ini yaitu didapatkan $60 \%$ responden dengan paritas multipara sehingga mendukung terjadinya KPD pada responden. hasil penelitian ini menunjukkan bahwa paritas yang berpengaruh terhadap Asfiksia yaitu pada Multipara. Pada ibu yang mengalami KPD sebanyak $12(60 \%)$ dan pada ibu yang tidak mengalami KPD sebanyak 8 $(40 \%)$.

Penelitian ini sejalan dengan Hasil Penelitian Arifah Istiqomah dan Yesi Astria (2014) menunjukkan bahwa berdasarkan paritas, sebagian besar responden adalah multipara yaitu 46 orang 
(59\%) dan dan paling sedikit grandemultipara yaitu 1 orang $(1,3 \%)$. Dalam penelitian ini multipara meduduki persentase terbanyak.

Insidensi terjadinya KPD berkisar antara $8-10 \%$ dari semua kehamilan. Pada kehamilan aterm, insidensinya bervariasi antara 619\%. Sedangkan pada kehamilan preterm, insidensinya $2 \%$ dari semua kehamilan. Hampir semua KPD pada kehamilan preterm akan lahir sebelum aterm atau persalinan akan terjadi dalam satu minggu setelah selaput ketuban pecah. Sekitar $85 \%$ morbiditas dan mortalitas perinatal disebabkan oleh prematuritas. KPD berhubungan dengan penyebab kejadian prematuritas dengan insidensi 30-40\%. Risiko yang daoat ditimbulkan akibat ketuban pecah dini adalah infeksi, penting bagi bidan melakukan deteksi dini terhadap infeksi. Tentukan ada tidaknya infeksi, tanda-tanda infeksi : suhu ibu $\geq$ $38^{\circ} \mathrm{C}$, air ketuban bercampur mekonium dan berbau.
Pemeriksaan air ketuban dengan tes LEA (Leukosit Esterase), leukosit darah >15.000/ mm3, janin mengalami takhicardi. mungkin mengalami infeksi intra uterine. Menurut teori salah satu komplikasi yang timbul akibat ketuban pecah dini bergantung juga pada usia kehamilan. Dapat terjadi infeksi maternal ataupun neonatal, persalinan prematur, hipoksia karena kompresi tali pusat, deformitas janin, meningkatnya insiden SC, atau gagalnya persalinan normal (Mochtar, 2011). Pecahnya ketuban terjadi oligohidramnion yang menekan tali pusat hingga terjadi asfiksia atau hipoksia. Terdapat hubungan antara terjadinya gawat janin dan derajat oligohidramnion, semakin sedikit jumlah air ketuban, maka janin semakin gawat. Ketuban pecah dini yang terjadi terlalu dini menyebabkan pertumbuhan janin terhambat, kelainan disebabkan kompresi muka dan anggota badan janin, serta hipoplasi pulmonal (Mochtar, 2011). 


\section{SIMPULAN}

Dari hasil uji statistik di dapatkan:

1. Terdapat hubungan antara usia ibu bersalin dengan kejadian asfiksia $(p$ value $=0,026)$

2. Tidak terdapat hubungan antara paritas ibu bersalin dengan kejadian asfiksia ( $p$ value $=$ $0,107)$

3. Terdapat hubungan yang signifikan antara usia kehamilan dengan kejadian asfiksia ( $p$ value $=0,988$ )

4. Tdak terdapat hubungan yang signifikan antara infeksi yang terjadi pada ibu bersalin dengan kejadian asfiksia ( $p$ value 0,451 )

5. Tidak terdapat hubungan yang signifikan antara gawat janin dengan kejadian asfiksia ( $p$ value 0,434 )

\section{UCAPAN TERIMA KASIH}

Ucapan terima kasih diberikan kepada STIK Budi Kemuliaan dan RSU Budi Kemuliaan.

\section{DAFTAR PUSTAKA}

Buku panduan praktis pelayanan kesehatan maternal dan neonatal, Jakarta, 2014
Prawirohardjo, S. (2010). Ilmu kebidanan. Jakarta: Yayasan Bina Pustaka Sarwono Prawirohardjo.

Prawirohadjo, S. (2014). Ilmu Kebidanan. Jakarta: Bina Pustaka Sarwono Parwirohardjo.

Wiknjosastro. 2008. Buku Acuan Asuhan Persalinan Normal. Jakarta: Yayasan Bina Pustaka - Sarwono Prawirohardjo.

Maryunani, Anik. 2013. Asuhan Bayi Baru Lahir Normal. Jakarta: ETN

Depkes RI. 2008. Profil Kesehatan Indonesia 2008. Jakarta: Departemen Kesehatan RI.

Kemenkes. 2010. Penanganan Persalinan Normal. Jakarta: Yayasan Bina Pustaka.

Data Survei Demografi dan Kesehatan Indonesia (SDKI) 2007

Data Survei Demografi dan Kesehatan Indonesia (SDKI) 20012

Data Profil Seksi Kesehatan Keluarga Dinkes DKI Jakarta 2017

Profil Kesehatan Indonesia, 2017

Arifah Istiqomah, Y. A. (2014). Hubungan Ketuban Pecah Dini dengan Kejadian Asfiksia.

Bayu Irianti, E. m. (2013). Asuhan Kehamilan Berbasis Bukti. Jakarta: Agung Seto.

Fadlun. (2011). Asuhan Kebidanan patologis. Jakarta: Salemba Medika.

Fatkhiyah, N. (2008). Hubungan Antara Persalinan Ketuban 
Pecah Dini Dengan Asfiksia Neonatorum di RSUD $d r$. Soeselo.

JNPK-KR. (2012). Asuhan persalinan Normal. Jakarta: Salemba Media.

Laurensia Yunita, F. W. (2014). Hubungan Ketuban Pecah Dini Dengan Kejadian Asfiksia Pada Bayi Baru Lahir di RSUD dr. H. Moch. Anshari Saleh Banjarmasin.

Manuaba.I.B.G. (2009). Buku aajar Patologi Obstetri. jakarta: EGC.

Nugroho, T. (2011). Obstetri. Jakarta: Medical Book.

Prawirohadjo, S. (2014). Ilmu Kebidanan. Jakarta: Bina Pustaka Sarwono Parwirohardjo.

Prawirohardjo, S. (2002). Ilmu kebidanan. Jakarta: Yayasan Bina Pustaka Sarwono Prawirohardjo.

Rukiyah, A. Y. (2010). Asuhan Neonatus, Bayi dan Anak Balita. Jakata: Trans Info Media.

Safa'ah, N. (2009). Hubungan Antara Ketuban Pecah Dini dengan Kejadian Asfiksia pada Bayi Baru Lahir Di RSUD dr. R. Koesma Tuban.

Vidia Atika Manggiasih, p. j. (2016). Asuhan Kebidanan Pada Neonatus, Bayi, dan Anak Pra Sekolah. Jakarta: Trans Info Media.

Marmi,dkk,.AsuhanKebidananPat ologi.Yogyakarta:Pustaka Pelajar, 2016.

Wiknjosastro. 2005. Faktor Risiko Kematian Ibu. Jakarta: EGC.
Manuaba. 2008. Gawat Darurat Obstetri Ginekologi \& Obstetri Ginekologi Sosial untuk Profesi Bidan. Jakarta: EGC.

Pudiastuti, Ratna Dwi. Asuhan Kebidanan Pada Ibu Bersalin Patologi. Yogyakarta: Nuha Medika, 2012.

Prawirohardjo, Sarwono. 2007. Ilmu Kebidanan. Jakarta: Yayasan Bina Pustaka 